\title{
Grade 9 learners' understanding of fraction concepts: Equality of fractions, numerator and denominator
}

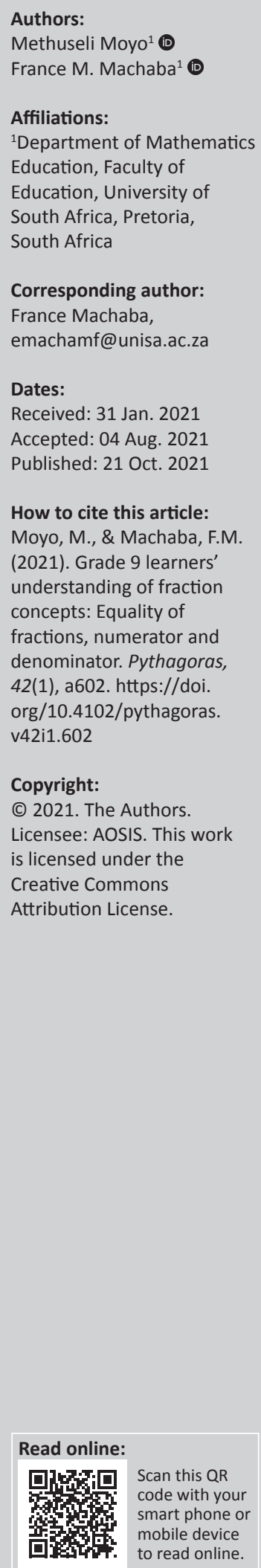

\begin{abstract}
Our research with Grade 9 learners at a school in Soweto was conducted to explore learners' understanding of fundamental fraction concepts used in applications required at that level of schooling. The study was based on the theory of constructivism in a bid to understand whether learners' transition from whole numbers to rational numbers enabled them to deal with the more complex concept of fractions. A qualitative case study approach was followed. A test was administered to 40 learners. Based on their written responses, eight learners were purposefully selected for an interview. The findings revealed that learners' definitions of fraction were neither complete nor precise. Particularly pertinent were challenges related to the concept of equivalent fractions that include fraction elements, namely the numerator and denominator in the phase of rational number. These gaps in understanding may have originated in the early stages of schooling when learners first conceptualised fractions during the late concrete learning phase. For this reason, we suggest a developmental intervention using physical manipulatives to promote understanding of fractions before inductively guiding learners to construct algorithms and transition to the more abstract applications of fractions required in Grade 9.
\end{abstract}

Keywords: fraction; equality; numerator; denominator; misconceptions; manipulatives.

\section{Introduction}

Transitioning from whole number concepts to rational numbers traditionally poses a considerable challenge to the mathematically developing mind and may become a stumbling block in the way of maturation in number conceptualisation (Durkin \& Ritle-Johnson, 2014; Simon, Placa, Avitzur, \& Kara, 2018).

Experience with whole numbers makes the transition to rational numbers somewhat abstract (Simon et al., 2018). Bruce, Bennett and Flynn (2014) explain that fractions are multiple digits (numerator and denominator) that represent one quantity, making different interpretations of fractions possible. Bruce et al. argue that a fraction has several meanings, depending on the context in which it is used: for example, a part of a whole, a part of a set, ratio and rate. To fully understand all situations in which fractions express different meanings and to discern which meaning applies in a particular context, some conceptual understanding is required.

Conceptual understanding in the context of this article refers not to isolated facts, but to the ability of learners to make meaningful connections between fractional elements such as the numerator and the denominator. For example, in their studies, Deringöl (2019) and Simon et al. (2018) found that learners faced challenges in terms of viewing the numerator and the denominator as representing a whole together. Learners tend to see a fraction as a pair of numbers representing quantities with no relationship implied between those quantities (Stafylidou \& Vosniadou, 2004). Furthermore, in his study, Deringöl found that learners had difficulty comprehending the principle of identical pieces in the piece-whole relationship. They failed to understand that an object must be divided into identical pieces when defining and representing fractions.

The Grade 9 learner results of the Annual National Assessments (ANA), from 2012 to its conclusion in 2018, present a bleak picture. This test was administered at phase exit levels: Grade 3 marks the end of the Foundations Phase (FP), Grade 6 the end of the Intermediate Phase (IP) and Grade 9 the end of the Senior Phase (SP). Over the years, a pattern of steep decline has emerged from one exit level to the next. In Grade 9, the performance dropped to 5\%. In 2014, only 3\% of Grade 9 learners countrywide achieved above $50 \%$ in the ANA (mathematics), according to the report by the Department of Basic Education (DBE, 2014, p. 63). Grade 9 is a threshold grade, the successful completion of which gives access to the SP or Further Education and Training (FET) phase. 
Several fraction concepts, including rate and ratio, are included in the Grade 9 curriculum, notably in formulae, algebraic expressions or equations. These also occur in various contexts in all mathematical content areas. Thus, a conceptual understanding of rational numbers and their applications is essential in Grade 9 mathematics.

\section{Literature review}

\section{Fractions as a transition to rational numbers}

The troublesome nature of teaching and learning fractions has been widely reported (Bruce et al., 2014; Gabriel, 2016; Stafylidou \& Vosniadou, 2004). The transition from whole numbers to rational numbers such as common fractions is gradually introduced during the first six years of schooling (Braithwaite \& Siegler, 2018). Braithwaite and Siegler's (2018) study found, resonating with our findings, that many learners' knowledge of fractions is adversely affected by whole number bias: the tendency to focus on the separate whole number components (numerator and denominator) of a fraction rather than on the fraction's magnitude (ratio of numerator to denominator). Several researchers, including Ni and Zhou (2005) and Brown (2019), have described initial rational number learning as an experience of conceptual change. The work of Siegler, Thompson and Schneider (2011) challenges the view that these differences are fundamental to rational number learning, proposing instead that children should be encouraged to see rational numbers and whole numbers as one unitary formal system, united by the property of magnitude. This property can be represented symbolically on the number line; that is, this property and the use of the ordered number line should be the basis for teaching rational numbers.

In their attempt to address the challenge of the transition from a whole number to a rational number, Van De Walle et al., (2016) illustrate in their textbook how children learn fractions, and then shows pre-service teachers the most effective methods of teaching fractions through hands-on, problem-based activities. The initial concrete mode of instruction is followed by pictorial and diagrammatical representations of fractions and by the end of the IP learners are expected to perform calculations with fractions using numerical symbols (Van de Walle, Folk, \& Bay-Williams, 2010). This transition is intended to prepare the IP learner for the formal abstract applications of rational numbers in algebra, geometry, probability, data handling and measurement applications in the SP. A critical component of the understanding of rational numbers and proportional reasoning aids the transition from informal (pre-algebra) to formal (algebra) mathematical thought; however, this is often handled as an add-on, after fraction and ratio concepts (Doyle, Dias, Kennis, Czarnocha, \& Baker, 2016), when a ratio should be expressed as a comparison of a part to a whole. For example, the ratio of the number of girls in a class (9) to the number of students in the class (16) can be written as the ratio of $\frac{9}{16}$.

The general difficulties that arise from learners' transition from whole numbers to rational numbers, including their development of proportional reasoning, are compounded by their struggle to advance from informal concrete to formal abstract work with fractions. Although the teaching protocol of moving from the concrete through representational work to symbolic work with fractions seems to follow a logical developmental sequence, we doubt whether it succeeds in equipping learners for the work with fractions that is required in the SP, specifically in Grade 9. In this article, we conclude that learners face challenges in demonstrating a flexible ability (the application of fractions to other examples, related concepts and contexts). It appears that the most basic fractional concepts have not taken root.

\section{Constructivism adapted from Piaget}

Piaget (1964a) believes that when the developing mind interacts with new situations or ideas, a continuous interplay of two cognitive processes occurs, namely:

- Accommodation happens when learners reflect on the new experience and realise that it does not fit into their existing schema; they, therefore, modify their cognitive structure to accommodate the new idea.

- Assimilation occurs when learners make meaning of the new idea by relating it to their existing knowledge, organising their cognitive structures to incorporate the new idea in their existing schema.

Piaget (1964a) argues that learners need information, concepts, ideas or a network of connected ideas to think, and they will think according to the knowledge they already have at their disposal (in their cognitive schema). The deadweight of facts learnt off by heart, by memory, without thought given to meaning (that is rote learning), robs the learner of the potential excitement of relating ideas or concepts to one another and the possibility of divergent and creative thinking (Van De Walle et al., 2016). What is inculcated in learners because of rote-memorised rules, in many cases, is the manipulation of symbols that have little or no attached meaning. This makes learning much more difficult because rules are much harder to remember than integrated conceptual structures that are made up of a network of connected ideas. Such learners' understanding of a whole divided into equal-sized portions is indicated in Figure 1. In addition, careless errors are not picked up by learners themselves because the task has no meaning for them: they are unable to anticipate the kind of result that might occur.

An integrated network of connected ideas brings about conceptual understanding. Understanding can be thought of as the measure of the quality and quantity of connections of an idea to existing ideas. For example, learners should see the numerator and the denominator in the fraction not as separate values, but as numbers that are related. Understanding depends on the existence of appropriate ideas and the creation

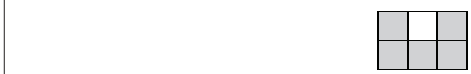

FIGURE 1: Example of a fraction as part of a whole. 
of new connections. The greater the number of appropriate connections to a network of ideas, the better the understanding. Skemp (1974) argues that learners' understanding could exist along a continuum. At one pole, the ideas are loosely connected or isolated from each other. This is the pole of so-called instrumental understanding (Van de Walle et al., 2016). At the other pole, an idea is associated with many others in a rich network of related ideas (the relationship between numerator and denominator, for example). This is the pole of so-called relational understanding. Knowledge learned in a rote way, for example without regarding the numerator and denominator as a unitary value, is almost always at the pole of instrumental understanding, where ideas are nearly always isolated and disconnected.

Noureen, Arshad and Bashir (2020) suggest that constructivism holds that learners are not blank slates or empty vessels waiting to be filled with knowledge. Instead, from a rich array of previous experiences, knowledge and beliefs, learners construct new knowledge. Gupta and Gupta (2017) agree that just as in cell theory, where all cells are explained as arising from pre-existing cells, knowledge already resides in the human mind. What is needed is ways to explore this knowledge. Piaget's (1964a) cognitive constructivism implies that learners engage with ideas on their own, work through tasks, sift through the material at hand and either accommodate or assimilate the present experience into their existing mental schemata. They do not merely absorb the ideas as teachers present them; rather, they are creators of their knowledge (Hatano, 1996).

The purpose of this study was to explore learners' understanding of fundamental fraction concepts, such as numerator and denominator, and of the fraction itself, used at Grade 9 level. It was based on the ideas of constructivism in a bid to understand whether learners' transition from the whole number to rational numbers would allow them to deal with more complex fraction concepts. The theory of constructivism was particularly pertinent in that when learners construct knowledge on the concept of a fraction by themselves, misconceptions inevitably arise. This means that misconceptions are part of learning; however, appropriate intervention is required to rectify such misconceptions.

\section{The concept of the fraction}

When establishing the foundations of the concept of the fraction, the following ideas should be applied.

\section{Conceptualising a fraction as part of a whole}

Fitri and Prahmana (2019) argue that most learners still consider a fraction as a meaningless symbol and assume that the numerator and the denominator are separate numbers. The fraction $\frac{1}{8}$ could not for instance be understood to mean the quantity formed by one part when a whole is partitioned into eight equal parts. The key to understanding fractions as part-of-a-whole is to identify the whole and the equal fractional parts. As such, fractions have meaning only concerning the whole to which they apply.

Van de Walle et al. (2016) explain that the conceptualisation of fractions concerns the relationship between the part and the whole. In an example using a geometric shape, a rectangle divided into six equal parts, each part equals one-sixth of the whole; therefore, five parts are five-sixths of the whole and six-sixths make one whole, as illustrated in Figure 1.

Van de Walle et al. (2016) emphasise the importance of the language used in learning fractions. To prevent misconceptions, they advise that in the acquisition of the concept, learners should be able to say, as in our example for instance, 'My whole is a rectangle. It is divided into six equal parts. Each part is a sixth of the whole'. Conversely, given the whole (undivided) rectangle, they should be able to explain that 'to find one-sixth of the whole, I divide it into six parts of equal size, and shade one part. The shaded part is one-sixth of the whole'.

\section{Conceptualising fractions as numbers}

Simon et al. (2018) argue that to explain fractions as part of geometric shapes is insufficient, as it excludes an understanding of some important aspects of fractions. In a 'part-of-a-whole' geometric shape, part shading clearly shows the fraction; however, it does not convey the idea of a fraction as a number. The notion of a fraction as a number means a fraction can be expressed in the form of $a / b$ where $a$ and $b$ are integers but not equal to 0. Similarly, Deringöl (2019) believes that the 'part-of-a-whole' conceptualisation limits the understanding that a fraction can be greater than 1 and it narrows thinking to the idea of partitioning one whole. Simon et al. (2018) advise that learners understand fractions as numbers that expand the number system beyond whole numbers, and recommend the use of number lines as a key representation tool to convey fraction concepts.

We share the concern of these scholars that defining a fraction as a part of a whole is only a part of the understanding of the concept. Nevertheless, in our study, we explored learners' understanding of a whole divided into equal-sized portions (Van de Walle et al, 2016). Representing a fraction as 'part-ofa-whole' forms part of many South African textbooks and as such has justifiable use in the fostering of this idea (Laridon et al., 2005).

\section{Conceptualising the fraction notation}

Alghazo and Alghazo (2017) believe that learners tend to see a fraction either as a division calculation on its own or as a set of two numbers written above and below a fraction line. In a study on equivalent fractions, Jigyel and Afamasaga-Fuata'i (2007) concluded that some learners perceived the components of fractions, the numerator and denominator, as two unrelated whole numbers, which led to misconceptions. In a bid to investigate the influence of this misperception on learning, Jigyel et al. (2007) conducted a test on learners to 
choose the most appropriate way of reading $\frac{2}{5}$. Options provided were: two-fifths, 2 over 5, 2 upon 5 and none of the above. Jigyel et al. found that two-fifths was the commonest answer, although a significant number of learners chose two over five. A learner selected from the 2 over 5 group explained that 'there is a two on a line above five, so it is two over five'. The separation of the 2 from the 5 may influence the perception that $\frac{2}{5}$ is not a number in its own right that can be positioned on the number line. Jigyel et al. (2007) warn that if learners acquire the fraction concept by counting the shaded and total number of parts in a geometric diagram, they may perceive fractions as a relationship between two unrelated counts. Seeing $\frac{2}{5}$ as shading two out of five parts may lead them to perceive $\frac{2}{5}$ as $2 \div 5$. This may result in learners recognising $\frac{2}{5}$ not as a single quotient value with a specific position on the number line, but rather as one number on the number line, divided by another number on the number line.

Deringöl (2019) clarifies the meaning of the components of fraction notation, arguing that most learners do not realise that the denominator and the numerator represent the partof-a-whole representation of a fraction. They do not understand that the bottom number is telling what is being counted and the top number is counting how many parts one has of the available whole. As a result, for $\frac{5}{6}$, for example, they might call 5 the numerator and 6 the denominator, yet the terms are meaningless to them (Van de Walle et al., 2016).

\section{Misconceptions}

Various conceptualisations of misconceptions exist in the literature. Some theorists emphasise the causal aspect, while others focus on the consequences of misconceptions. In our opinion, both perspectives hold value and should be explored, as we do in this study.

\section{Perspectives on the nature of misconceptions}

The causal perspective of misconceptions: For Smith, diSessa and Roschelle (1994), misconceptions are flawed ideas that are firmly held by learners and that interfere with learning. Drawing on the notion that learners do not enter the learning situation as blank slates, Smith et al. argue that as they interact with new material, learners interlink ideas they already have. Therefore, when learners construct knowledge, the activity of reconstructing and reorganising what they already know and synthesising new knowledge may include the synthesis of misconceptions.

Olivier (1989) asserts that misconceptions are errors made repeatedly, each time learners deal with similar situations, with the result that the repetitive misappropriation of a concept eventually becomes routine for the learner. Vamvakoussi and Vosniadou (2010) explain misconceptions as 'synthetic concepts' as they are the by-product of a broadening of knowledge of the number system from natural numbers to rational numbers. Ojose (2015) describes misconceptions as

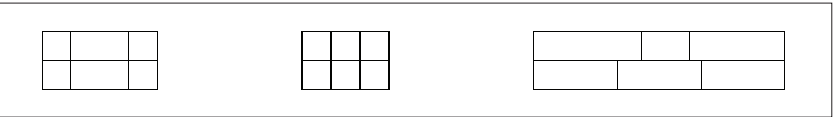

FIGURE 2: Rectangle divided into six parts.

misunderstandings and misinterpretations based on incorrect meanings. In this regard, we cite the faulty understanding of the equality of fractional parts as an example. Frequently, the qualification that fractional parts are equal is misunderstood. Learners might, for example, say that the parts in the rectangles in Figure 2 are sixths, not taking into account that in these rectangles the whole is not divided into equal parts.

Prediger (2006) describes the obstacles faced by learners as didactic stumbling blocks created by the method of teaching, or epistemological obstacles stemming from the structure of mathematical content. One way or the other, that which misleads is the source of obstacles in the way of conceptual understanding. Learners seemingly construct their knowledge based on their own experiences. If these experiences provide them with only limited views of a particular concept, this may close their minds to other related aspects of the concept. These narrow experiences result in constructions that inhibit further understanding and are called limiting constructions. Pitkethly and Hunting (1996) refer to them as inhibitors - mechanisms that inhibit the development of new and enlarged rational number knowledge. Based on findings of other research projects, D'Ambrosio and Mewborn (1994) anticipated that fourth-graders in their study would have constructed many fraction schemes that would limit their further understanding. Taking a different view to the studies mentioned above, however, they avoided labelling the children's constructions as misconceptions because they believe it is important to view children's constructions as objects for a study that can provide insight into and a new understanding of their thinking.

The consequential perspective of misconceptions: Rather than delving into the possible causes of misconceptions, Sarwadi and Sharhill (2014) focus on their result or effect, namely systematic errors as consequences of misconceptions.

Both the causal and the consequential perspectives imply that misconceptions are an undisputed reality and an inevitable part of knowledge development that will always be there; however, just as they came about, so they can be corrected and appropriately dealt with, if and when they surface. In our study, we started with the consequence (the error manifested) and moved to the cause. Confrey (1990, p. 18) asserts: 'A misconception is a "conceptual stumbling" block, inconsistent semi-autonomous schemes, and cognitive process responsible for errors in problem-solving'.

\section{Manifested misconceptions in fractions}

Resnick et al. (1989) classified misconceptions in fractions into three categories, of which the whole number misconception is particularly pertinent. The whole number misconception is what $\mathrm{Ni}$ and Zhou (2005) refer to as the whole number bias, limiting one's view of numbers to whole numbers. Bruce et al. (2014) hold that this bias is the result of 
an emphasis on whole number counting at an early age, which tends to reinforce a stubborn conceptualisation of numbers as whole numbers. In keeping with the argument of Jigyel et al. (2007), Durkin and Rittle-Johnson (2014) believe that the transition from natural numbers to rational numbers opens the way for the development of misconceptions.

Van de Walle et al. (2010) argue that learners build on their prior knowledge of whole numbers, which may both support and inhibit their understanding of fractions. One such example would be the common misconception where learners over-generalise their understanding of whole numbers, subsequently regarding both the numerator and denominator as whole numbers and not as an element of the new fraction concept. Ashlock (2010) describes the nature of manifested misconceptions as learners trying to make sense of fractions by either over-generalising or over-specialising the rules they know already. This implies that as much as previous knowledge is essential, it contains elements that can prejudice conceptualisation in fractions. Machaba (2016) asserts that misconceptions are likely to arise when learners construct knowledge by reconstructing and reorganising prior knowledge with new knowledge. Inappropriate linking of prior knowledge to new knowledge may jeopardise conceptual development. This study was conducted to explore the understanding of fundamental fraction concepts used in more advanced applications that are required at the Grade 9 level. In this article, we argue that introducing numerical fraction notation before fraction concepts are properly understood could be regarded as malpractice. For this reason, we suggest the developmental intervention of using physical manipulatives as a remedy for ill-conceived fraction concepts before guiding learners to inductively construct algorithms and transitions to the more abstract applications of fractions, as required in Grade 9.

Work on fractions by Grade 9 learners was explored by posing the following research questions:

- How do Grade 9 learners define, describe and represent the concept of fractions?

- What misconceptions are evident when learners define, describe and represent problems involving fractions?

- What are the root causes of learners' misconceptions in the learning of fractions?

\section{Research design and methodology}

In this qualitative study, an instrumental case study research design was employed, using a test and interviews as data collection methods. In the larger study, a test was administered, consisting of four questions with 15 items in total. For this article, we have chosen four question items because they are particularly relevant to our argument. The purpose of the test was to assess learners' conceptual understanding of the concept of fractions. As learners define fractions, they demonstrate what they know and understand about this concept. Eight learners were purposively chosen for an interview based on how they answered the test items.
A Grade 9 class of 40 learners completed the test on the topic of fractions. From the FP onwards, these learners had been exposed to fraction terminology, notation, calculations using all four operations, related applications such as rate and ratio, and problem-solving involving fractions. The first author marked the tests and classified each learner's responses to each question as correct, incorrect or partially correct (see Table 2). Codes were randomly assigned to each learner to serve as references whenever necessary, for instance L1 for Learner 1. The interview was tape-recorded so that the researchers could transcribe the information correctly.

\section{Ethical considerations}

Ethical clearance was obtained from the University of South Africa, College of Education Ethics Review Committee (2018/11/14/46511/024/43/MC).

The first author went through the required process, applying for ethical clearance from the university. Since the study was conducted at a government school, he had to follow protocol and obtain clearance from all structures that govern the school up to the district level. He sought permission from the Gauteng Department of Education (GDE) to research one of its institutions. He requested permission from the principal of the school to conduct the study with Grade 9 learners and described the purpose and the rationale of the study. The school governing body (SGB) was informed of the study in a meeting with the principal. After permission was granted, the Grade 9 learners were informed of the study in good time so that they could decide whether to participate voluntarily in the study. Those learners who agreed to participate were guaranteed anonymity and confidentiality. Pseudonyms were used in the study, and responses were kept confidential. Researchers made it clear to participants that the study had nothing to do with their course work, and would not contribute towards promotion marks.

\section{The main instrument for data collection}

Learners' written responses to the test constituted the main body of data analysed in the study. The four (out of 15) test items selected for this article and under discussion here are shown in Figure 3.

The introductory section of the test was not at Grade 9 level, where the key concepts and skills include, among others, calculations with common fractions and mixed numbers using all four operations. The rational numbers in these operations include exponents and roots of fractions and require prior knowledge of multiples and factors, equivalent forms of fractions (common and decimal fractions and percentage), reciprocals and problem-solving with fractions. Fractions then occur in applications in other mathematics content areas, other than numbers, operations and relationships, such as algebra, geometry and data handling in measurement contexts.

Whereas Grade 9 is the exit level of the SP, the concepts and skills tested in the items in this test fell midway in the 
curriculum for Term 1 of Grade 4, the first grade of the IP. At this stage of their schooling career, learners should have transitioned from the FP with sufficient prior knowledge to complete the items in Questions 1.1 to 1.4 in Figure 3. This set of items could appear as is, in a Grade 4 textbook.

The testing of these basic fraction concepts and skills in the present study was intended to regress across grades and phases to determine the roots of problems manifested in Grade 9 learners' dealings with the complex requirements of the four test items. At face value, this leap would seem rather optimistic, since the researchers' work with Grade 9 learners had alerted them to the possibility of gaps in their knowledge originating as far back as Term 1 of Grade 4, if not further.

\section{Findings}

In the initial step of the analysis, the outcomes of learners' written responses were categorised as correct (C), partially correct (PC) or incorrect (IC). The use of tables, percentages and frequencies is associated with quantitative research; in

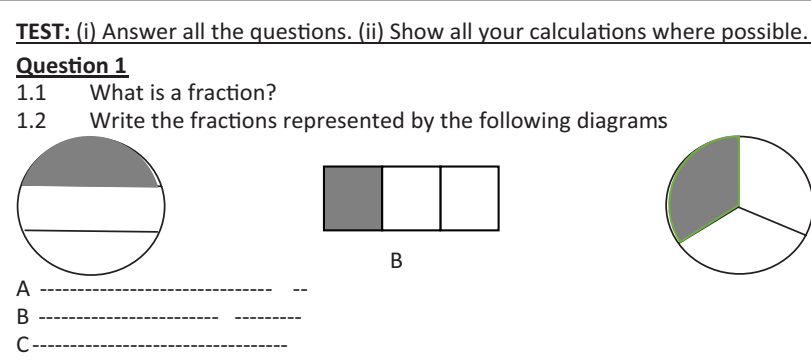

1.3 a) Shade $\frac{3}{5}$ of the rectangular mat below.

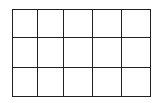

b) Write down in words what you would do to a shade $\frac{3}{5}$ of the rectangular mat.

1.4 \begin{tabular}{|l|l|l|l|l|}
\hline & & & & \\
\hline
\end{tabular}

In the fraction $\frac{3}{5}$, what does the 5 mean?

What does the 3 mean?

FIGURE 3: Written test (selection of four items). this case, the researchers wished to determine the extent of the prevalence of misconceptions to enable valid inferences and further analysis. Table 1 presents the classification of all 40 learners' responses. The eight learners who were selected for follow-up interviews are highlighted in bold.

The number and percentage of correct answers in items 1.1-1.4 are indicated in Table 2.

Discernible patterns of misconceptions and faulty understanding showed up in learners' written responses. The most common misconceptions demonstrated in learners' written responses are explained in Table 3.

Particularly concerning was the fact that these basic constituents of the fraction concept were lacking or faulty in an average of $85 \%$ of the Grade 9 learners tested. The researchers assumed that learners who lacked an understanding of these basic fraction concepts would be unable to cope with the complex requirements of Grade 9 fraction applications.

Below are the verbatim verbal responses of four of the eight learners (L6, L11, L15 and L17) who were interviewed after the tests had been marked. The interview responses supported the patterns we observed in the written responses as explained in Table 3 and provided more insight into the reasoning that preceded the written responses.

In the following section, we report various learners' verbal responses to each question. To avoid repetition, for each question we selected participants whose answers reflected those of most of the interviewees.

\begin{tabular}{llcc}
\multicolumn{4}{l}{ TABLE 2: Correct learner solutions per test item. } \\
\hline Item & Knowledge or skill tested & Correct $(\boldsymbol{n}=\mathbf{4 0})$ & Percentage \\
\hline 1.1 & $\begin{array}{l}\text { Defining, describing or explaining the } \\
\text { concept fraction }\end{array}$ & 0 & $0 \%$ \\
1.2 & $\begin{array}{l}\text { Recognising a fraction as a whole divided } \\
\text { into equal parts }\end{array}$ & 1 & $3 \%$ \\
$1.3 \mathrm{a}$ & $\begin{array}{l}\text { Shading three-fifths of fifteen equal parts } \\
\text { in a rectangle }\end{array}$ & 8 & $20 \%$ \\
$1.3 \mathrm{~b}$ & $\begin{array}{l}\text { Describing in words how three-fifths of } \\
\text { fifteen was calculated before shading }\end{array}$ & 7 & $18 \%$ \\
1.4 & $\begin{array}{l}\text { Explaining the meaning of numerals 3 and } \\
\mathbf{5} \text { in the fraction notation of three-fifths }\end{array}$ & 11 & $27 \%$ \\
\hline
\end{tabular}

TABLE 1a: Learner responses to test items 1.1 to 1.4 in three categories.

\begin{tabular}{|c|c|c|c|c|c|c|c|c|c|c|c|c|c|c|c|c|c|c|c|c|}
\hline Item & L1 & L2 & L3 & L4 & L5 & L6 & L7 & L8 & L9 & L10 & L11 & L12 & L13 & L14 & L15 & L16 & L17 & L18 & L19 & L20 \\
\hline 1.1 & PC & PC & IC & PC & IC & PC & PC & IC & IC & IC & IC & IC & IC & PC & PC & IC & PC & IC & IC & IC \\
\hline 1.2 & IC & IC & PC & IC & IC & IC & IC & IC & IC & IC & PC & IC & IC & PC & C & IC & IC & IC & IC & IC \\
\hline $1.3 a$ & IC & IC & IC & PC & IC & C & IC & IC & IC & IC & IC & $C$ & IC & IC & C & IC & IC & IC & IC & IC \\
\hline $1.3 b$ & IC & IC & IC & PC & IC & C & IC & IC & IC & IC & IC & IC & PC & IC & C & IC & IC & IC & IC & IC \\
\hline 1.4 & IC & IC & IC & IC & PC & C & IC & IC & IC & C & C & IC & C & IC & C & IC & IC & IC & IC & IC \\
\hline
\end{tabular}

TABLE 1b: Learner responses to test items 1.1 to 1.4 in three categories.

\begin{tabular}{llllllllllllllllllllllll}
\hline Item & L21 & L22 & L23 & L24 & L25 & L26 & L27 & L28 & L29 & L30 & L31 & L32 & L33 & L34 & L35 & L36 & L37 & L38 & L39 & L40 \\
\hline 1.1 & IC & IC & IC & IC & IC & PC & IC & IC & PC & PC & IC & PC & PC & PC & PC & IC & PC & PC & PC & PC \\
1.2 & IC & IC & IC & PC & PC & PC & IC & IC & PC & PC & IC & PC & IC & PC & IC & PC & IC & IC & IC & IC \\
1.3a & IC & IC & C & IC & IC & C & C & IC & IC & IC & C & IC & IC & IC & IC & IC & IC & IC & C & IC \\
1.3b & IC & IC & C & IC & IC & C & IC & IC & C & IC & C & IC & IC & C & IC & IC & IC & IC & IC & IC \\
1.4 & PC & C & IC & IC & IC & C & C & IC & IC & C & PC & IC & C & PC & IC & C & IC & IC & IC & IC \\
\hline
\end{tabular}

$\mathrm{C}=$ correct, $\mathrm{PC}=$ partially correct, $\mathrm{IC}=$ incorrect. 
TABLE 3: Most common misconceptions and faulty understanding in items 1.1 to 1.4 .

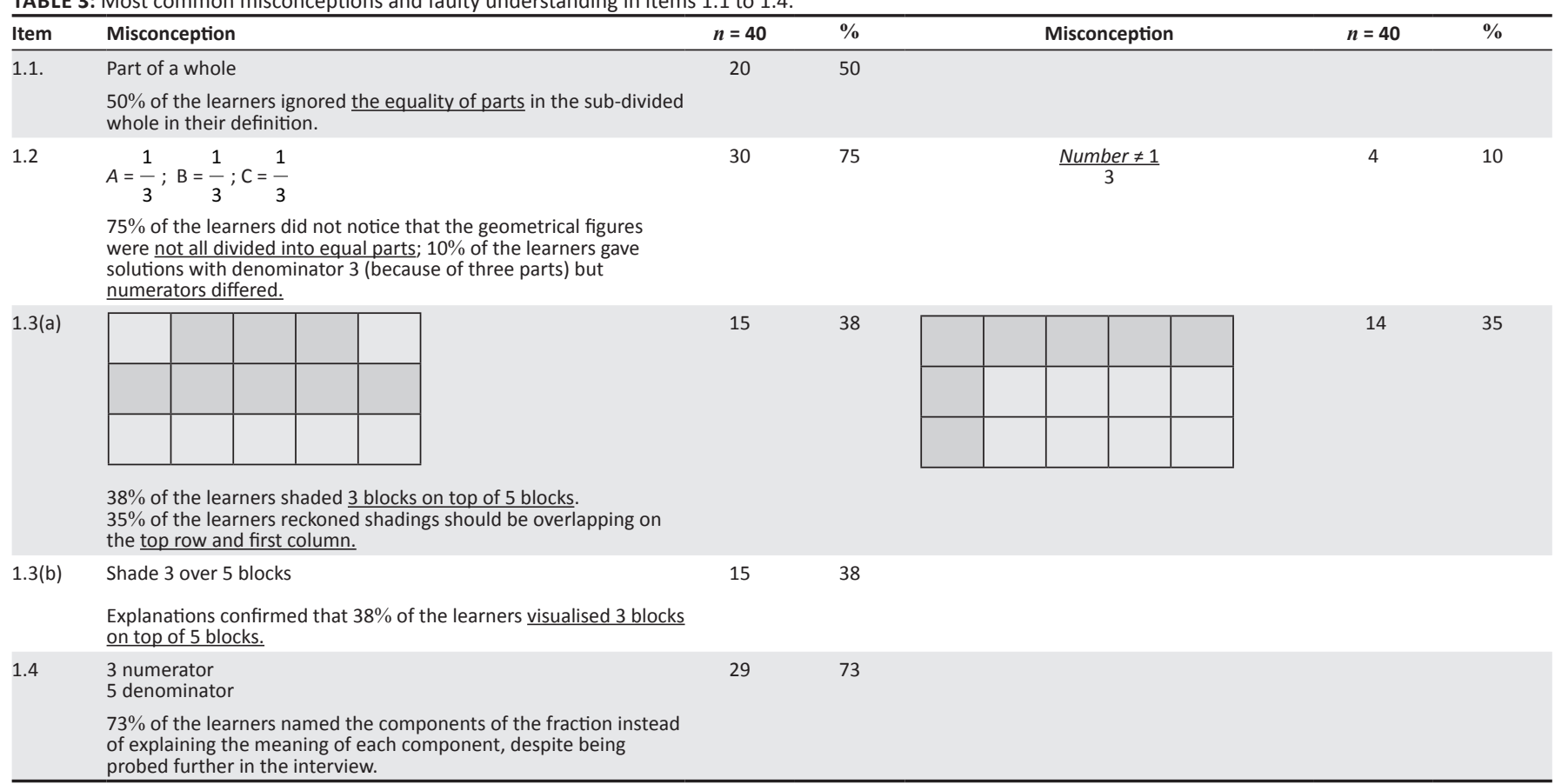

TABLE 4: Verbal responses of selected participants about Question 1.1.

\section{Item Verbal responses}

L6 Ok, when you eat a slice of pizza it is a fraction.

$R \quad$ If you cut out a section, will the remaining part be a fraction also?

L6 No! The part of a whole cut out or removed is the one that is a fraction.

$\mathrm{R} \quad$ Why not the remaining part?

L6 The removed part is like the shaded part of a whole which is used for showing fractions.

L11 When you buy a cake and cut it into two halves, that is a fraction and to write the fraction you put a whole number on top of another whole number.

L15 A piece of something complete.

R Say I cut a piece of a cake, it is a fraction according to you. What about the remaining cake?

L15 It is another fraction because it is also part of something complete.

L17 A number formed by two numbers.

$\mathrm{R} \quad$ What happens with two numbers to form this other number?

L17 The two numbers, one is the numerator and the other is the denominator.

R Please elaborate.

L17 Yes, the numerator shows the number of parts shaded in a shape divided into parts shown by the denominator.

\section{Question 1.1 What is a fraction?}

Table 5 contains selected verbatim responses from L6, L11, L15 and L17 during the interview. Interviewees responded to questions and prompts from the researcher (R) about Question 1.1.

The main concerns arising from these responses were:

- The idea of fractions as equal parts of a whole is distorted.

- The phenomenon fraction is muddled, probably by the (too early) introduction of fraction notation as numerical symbols, which were probably misunderstood at the time they were taught.

- The routine use of diagrams such as two-dimensional geometric shapes or the picture of a pizza seems to have had limiting effects on true conceptualisation.

- The terms are used as empty and meaningless words.
TABLE 5: Verbal responses of selected participants about Question 1.2.

\begin{tabular}{ll}
\hline Item & Verbal responses \\
L6 & $\begin{array}{l}\text { All show wholes divided into three parts so they represent the same } \\
\text { fraction. }\end{array}$ \\
L6 & And the fraction represented is $\frac{1}{3}$ ? \\
L11 & Yes, one whole divide by 3 hence $\frac{1}{3}$. \\
$R$ & Ok, so what matters is the number of parts the shapes are divided into? \\
L11 & Yes, that is where the denominator and name come from. \\
L38 & Dividing a whole into parts tells you what fraction you are making. \\
$R$ & How do the fraction and parts relate? \\
L38 & If there are five parts, for example, fifths, the fraction is $\frac{1}{5}$ but, in this \\
& case, there are three parts, thirds, so the fraction shown is $\frac{1}{3}$.
\end{tabular}

\section{Question 1.2 Write the fractions represented by the following diagrams}

Table 6 contains verbatim responses of L6, L11 and L38 on the questions and prompts of the researcher (R) during the follow-up interview. The responses pertain to Question 1.2.

Verbal explanations by L6, L11 and L38 fairly represent the opinions of all interviewees. Although test item 1.2 had shortcomings in that the idea of fraction-as-equalparts of a whole could not be fairly tested by this item with three different fraction diagrams, the misunderstanding of fractions as unequal parts of a whole became particularly evident in learners' answers to this item and was confirmed by their responses in the interview. The main concern here was that learners failed to recognise that the parts in Diagram A (circle) were unequal and the shaded part did not qualify as a third, unlike those in Diagram B and Diagram C, which were equal parts. 


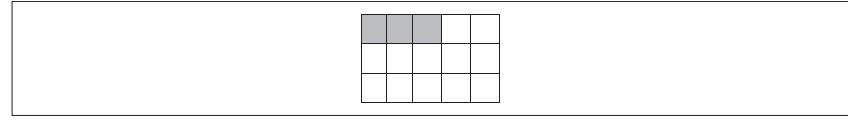

FIGURE 4: L6's demonstration of Question 1.3(a)

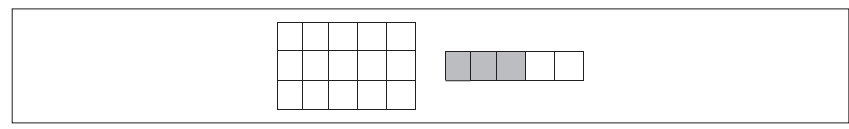

FIGURE 5: L17's illustration for Question 1.3(a).

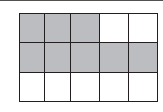

FIGURE 6: L34's illustration for Question 1.3(a).

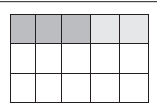

FIGURE 7: L38's illustration for Question 1.3(a).

TABLE 6: Verbal responses of L6 on Question 1.3(a) and (b).

\begin{tabular}{|c|c|}
\hline Item & Verbal responses \\
\hline L6 & I shaded three blocks. \\
\hline $\mathrm{R}$ & Why did you shade three blocks? \\
\hline L6 & $\begin{array}{l}\text { The numerator shows the number of parts that must be shaded. As } \\
\text { the numerator is three, I shaded three blocks. Got confused though, I } \\
\text { expected only five blocks. }\end{array}$ \\
\hline $\mathrm{R}$ & If I may ask, what fraction does your diagram represent as it is now? \\
\hline L6 & $\frac{3}{15}$, that's why I said there must be five blocks only. \\
\hline $\mathrm{R}$ & Why only five blocks? \\
\hline L6 & $\begin{array}{l}\text { The denominator shows the number of parts the shape is divided } \\
\text { into. Since the denominator is five, there have to be five blocks in } \\
\text { one whole. }\end{array}$ \\
\hline $\mathrm{R}$ & What is the relationship between $\frac{3}{5}$ and $\frac{6}{10} ?$ \\
\hline L6 & $\frac{6}{10}$ is $\frac{3}{5}$ times two. \\
\hline $\mathrm{R}$ & How so? \\
\hline L6 & $\frac{3}{5}+\frac{3}{5}=\frac{6}{10}$ \\
\hline
\end{tabular}

TABLE 7: Verbal response of L17 on Questions 1.3(a) and (b).

\begin{tabular}{ll}
\hline Item & Verbal responses \\
\hline$R$ & Why did you draw a separate diagram? \\
L17 & I only need five blocks to represent $\frac{3}{5}$ \\
L17 & But there were 15 blocks. \\
$R$ & Ya, I chose the 5 I need. \\
L17 & What is the relationship between $\frac{3}{5}$ and $\frac{6}{10} ?$ \\
$R$ & $\frac{6}{10}$ divide by two is $\frac{3}{5}$. \\
L17 & How so? \\
\hline
\end{tabular}

Instead, when a shape was divided into three parts, for example, they interpreted all parts as thirds, irrespective of their size.

\begin{tabular}{ll} 
TABLE 8: Verbal response of L34 on Questions 1.3(a) and (b). \\
\hline Item & Verbal responses \\
\hline$R$ & $\begin{array}{l}\text { Make me understand the way you shaded. } \\
\text { I shaded three blocks on top of five blocks, three blocks } \\
\text { over five blocks. }\end{array}$ \\
$R$ & $\begin{array}{l}\text { Why? } \\
\text { L34 }\end{array}$ \\
& $\begin{array}{l}\text { The fraction is } 3 \text { over } 5, \text { so three shaded parts must be } \\
\text { over or on top of five shaded parts so that it is easily } \\
\text { seen indicating } \frac{3}{5}\end{array}$
\end{tabular}

TABLE 9: Verbal response of L38 on Question 1.3(a) and (b).

\begin{tabular}{|c|c|}
\hline Item & Verbal responses \\
\hline $\mathrm{R}$ & Make me understand the way you shaded. \\
\hline L38 & $\begin{array}{l}\text { I shaded three out of five blocks and had to use different } \\
\text { colours to show which five blocks have I chosen to use. }\end{array}$ \\
\hline $\mathrm{R}$ & So you used five blocks only? \\
\hline L38 & Yes, isn't the fraction is $\frac{3}{5} ?$ \\
\hline $\mathrm{R}$ & Of course, $\frac{3}{5}$, meaning...? \\
\hline L38 & $\begin{array}{l}\text { Meaning shade three out of five. I had to choose my own } \\
\text { five and leave the rest. }\end{array}$ \\
\hline $\mathrm{R}$ & What happens with the rest of the blocks? \\
\hline L38 & They are not part of my answer, I only used five blocks. \\
\hline $\mathrm{R}$ & What is the relationship between $\frac{3}{5}$ and $\frac{6}{10}$ ? \\
\hline L38 & Two times $\frac{3}{5}$. \\
\hline $\mathrm{R}$ & Two multiplied by $\frac{3}{5}$ ? \\
\hline L38 & Yes. \\
\hline
\end{tabular}

Question 1.3 (a) Shade $\frac{3}{5}$ of the rectangular mat below. (b) Write down in words what you will do to a shade $\frac{3}{5}$ of the rectangular mat

Figures 4 to 7 and Tables 6 to 9 reflect the written and verbal responses about Question 1.3 (a) and (b) by four selected interviewees, L6, L17, L34 and L38.

This question tested very simply the idea of a fraction of a set made up of several objects. In this case, there are 15 blocks on a mat, with three blocks constituting one-fifth of the set. Most learners misunderstood this conceptualisation of a fraction. Instead, they tried to represent the numerical symbol of the fraction in a visual form by shading three blocks and five blocks. Most of these learners shaded three blocks on top of five blocks, in keeping with fraction notation. Working with 15 squares was difficult for some, so they used five little squares - the number they thought they needed.

\section{Question 1.4: In the fraction $\frac{3}{5}$, what does the 5 represent? What does the 3 represent?}

The responses in Table 10 from L6, L15, L17 and L38 were common to all respondents.

This question was focused on the interpretation of a fraction in terms of its components. Instead of explaining the meaning 
TABLE 10: Verbal response of L6, L13, L15 and L38 on Question 1.3(a) and (b).

\begin{tabular}{|c|c|}
\hline Item & Verbal responses \\
\hline L6 & $\begin{array}{l}3 \text { is the numerator because it is the top number in a } \\
\text { fraction and } 5 \text { is the denominator. After all, it is the } \\
\text { bottom number in a fraction. }\end{array}$ \\
\hline$R$ & $\begin{array}{l}\text { Do you know what the top number tells us about the } \\
\text { fraction, and what the bottom number tells us about the } \\
\text { fraction? }\end{array}$ \\
\hline L6 & $\begin{array}{l}\text { The denominator tells how many parts the shape is cut } \\
\text { into and the numerator is for the shaded parts. }\end{array}$ \\
\hline L15 & A denominator is a number that gives the fraction a name. \\
\hline $\mathrm{R}$ & A name how? Please elaborate. \\
\hline L15 & $\begin{array}{l}\text { For example, if the denominator is 5, fifths, } 6 \text {, sixths, and } \\
\text { so on. }\end{array}$ \\
\hline $\mathrm{R}$ & What about the numerator? \\
\hline L15 & The numerator is the number divided by the denominator. \\
\hline L17 & Three is the numerator and five is the denominator. \\
\hline $\mathrm{R}$ & Yes, I agree with you; what do they mean? \\
\hline L17 & It means three out of five. \\
\hline $\mathrm{R}$ & $\begin{array}{l}\text { Still, I need clarity on what three means and what five } \\
\text { means in three out of } 5 \text { ? }\end{array}$ \\
\hline L17 & Three parts out of five parts. \\
\hline L38 & Three is the numerator and five is the denominator. \\
\hline $\mathrm{R}$ & Yes, I agree with you, but what do three and five mean? \\
\hline L38 & It means three divides by five. \\
\hline $\mathrm{R}$ & $\begin{array}{l}\text { Ok, let me put it this way. From the three divides by five, } \\
\text { what does three as a numerator mean and what does five } \\
\text { as a denominator mean? }\end{array}$ \\
\hline L38 & $\begin{array}{l}\text { It means how many times five goes into three. Five is } \\
\text { dividing into three. }\end{array}$ \\
\hline
\end{tabular}

of each component, though, most learners provided a rote answer; they felt it sufficient to label 5 as the denominator and 3 as the numerator. How teachers had tried to explain fraction notation and the function of the numerals became clear from these answers; however, whether the numerals had meaning for the learners in terms of the fraction of which they formed part could not be determined. Common among learners' responses were notions such as:

- The idea of something being cut into parts, and then counted.

- The top number is out of the bottom number (like a test score, 3 out of 5).

- The position of the numerals: the top number and the bottom number.

- The top number is divided by the bottom number.

\section{Discussion and conclusion}

One objective of this study was to gain insight into Grade 9 learners' level of understanding of the fundamental concepts of fractions. In the data collection process, all participants wrote a test and the researchers conducted a follow-up interview with $20 \%$ of the sample to establish how learners had reasoned while completing the test. The results discussed in the previous section led us to conclude that the understanding of basic fraction concepts that is required at the Grade 4 level was almost non-existent among the Grade 9 participants in this study.

\section{Learners have a partial understanding of a fraction as part-of-a-whole}

\section{The equality of fraction parts}

Most learners used words such as 'sharing', 'dividing' and 'cutting' when defining a fraction; 50\% of the learners defined a fraction as a part of a whole, and L15 explained it as 'a piece of something complete'. 'Piece-whole' is the most basic concept in fractions. However, it appears that most learners experienced difficulties in mastering this concept. This may have been the only meaning learners had encountered in the classroom. Learners also had difficulty with the principle of identical pieces in the piece-whole relationship. They failed to understand that an object must be divided into identical pieces when defining and representing fractions. The question of how many identical pieces the whole was divided into, and of the number of these pieces that students were to colour in or select, was not understood. Evident in these responses was an absence of the qualification that fractional parts are equal shares or equal portions of a whole unit (Van de Walle et al., 2016). For example, in this study learners referred to three partitions in an object as 'thirds', irrespective of the size of the parts. This resonates with what Altıparmak and Özüdoğru (2015) found: the learners in their study had partitioning misconceptions, that is, using unequal parts of a whole while adding. They also misunderstood how to add the numerators and denominators of fractions. In a study of Turkish learners, Deringöl (2019) found that they had difficulty in dividing a whole into equal fraction pieces: they demonstrated misconceptions by failing to indicate in their drawing that each piece was identical. It was evident from their incorrect definitions that learners' faulty prior knowledge of fractions and errors such as dividing an object into unequal parts had influenced their conceptual understanding of fractions.

Learners in this study could not add new knowledge to their existing knowledge because they could not make sense of what they had already been taught (Machaba, 2016). They could not organise, structure or restructure their experience in the light of available schemes of thought (Van de Walle et al., 2016). If they are to overcome these difficulties, the piece-whole relationship should be taught first to learners when teaching fractions to develop prior knowledge of the concept of fractions. Learners will then be able to build on this knowledge as they continue to learn about mathematics.

\section{Regarding the numerator and the denominator of a fraction as separate}

Learners could define a fraction as a number formed by two numbers. L17 said, for example, 'it is a number formed by two numbers'. Learners could understand the numerator and the denominator in the fraction as separate values, but they did not realise that these numbers were related. They could not conceive that the numerator and the denominator represented a whole (Deringöl, 2019; Simon et al., 2018). They could see that a fraction was a pair of numbers representing quantities, but with no relationship implied between those quantities (Stafylidou \& Vosniadou, 2004). They may have understood that the first number was reflected in the number of shaded parts and that the second number corresponded to the number of total parts. 


\section{The scope of fractions}

No learner included fractions larger than 1 as part of their fraction definition. This led us to conclude that the part-of-awhole conceptualisation had limited their understanding of fractions to values between 0 and 1. L6, for example, said, 'when you eat a slice of pizza it is a fraction'. Learners perceived a fraction as deriving from a full set of parts making up the whole. A key effect of this conception was their inability to conceptualise an improper fraction, as having more parts than the number of parts in the source of those parts, the whole, did not make sense to them (Deringöl, 2019; Kieran, 1981; Simon et al., 2018). When learners related the fraction concept to real life, they referred to solitary items. Our observation was similar to that of Deringöl (2019) who argues that the 'part-of-a-whole' definition limits the development of the idea that a fraction can be greater than 1 .

\section{Fractions of a set}

Learners' definitions excluded the notion that fractions can be formed by part of a collection of discrete items. Jigyel et al. (2007) found that this limitation may be mostly the result of linking fractions to pictures of shaded parts of a model such as circles or rectangles, and less frequently to part of a group. In our study, we observed that even when the geometrical figure constituted a set of equal parts (Question $1.3[\mathrm{a}]$ and [b]), this was not recognised as such and learners struggled to make sense of it in terms of their unitary fraction concept.

We conclude that the partial understanding of fractions might be traced back to the definition of a fraction as 'part of a whole', encountered in several South African textbooks, such as Laridon et al. (2005). It was clear from learners' responses that they had a limited understanding of the term 'fraction'.

\section{Terms used when learning fractions are hollow words}

Learners could label but not explain the meaning of the 3 and the 5 in the fraction $\frac{3}{5}$ Almost all said that 3 was the numerator and 5 the denominator, without explaining what this meant. Learners did not comprehend the piece-whole relationship between the numerator and the denominator: they failed to understand that pieces constitute the whole and that the numerator is a piece of that whole, nor did they realise that the numerator and the denominator are related. Most were unaware that the bottom part of the fraction indicates how many parts the whole is divided into and is the name of a fractional part. If the number is 5 , for instance, it means we are counting the fifths. Nor did they understand that the top part of the fraction tells them how many of the parts are shaded or identified. The top number counts or enumerates. The numerator thus indicates the number of fifths they should consider or count (Van de Walle et al., 2016).

Moreover, fraction jargon appeared to be procedural rather than relational, without the true meaning being attached to expressions such as part of a whole, equal parts, two over three, three divided by five, a piece of something, a section cut from something, numerator on top and denominator at the bottom. This corresponds to findings by Jigyel et al. (2007) and Deringöl (2019); in their studies, learners could not read fractions correctly as they did not fully understand the concepts of numerator and denominator. They would read $\frac{3}{5}$ as 3 over 5 , for example, which obscured the meaning of numerator and denominator. If they had understood it, they would have read it as three-fifths: 3 as a number that counts and 5 as a number that indicates what is being counted.

Rather than relational understanding, learners should have developed an instrumental understanding of fractions, what Skemp (1976) describes as 'rules without reasons'. Indeed, learners wavered between unrelated fragments of fraction learning; they tried various perspectives, such as the quotient sub-construct and the whole number perspective, yet their knowledge remained devoid of meaning and, as such, completely dysfunctional as a tool with which to solve algebraic or context-based problems at Grade 9 level.

\section{Getting to the root of the problem}

While we do not have convincing data from learners' solutions strategies to support the root of the problem, the interviews seemed to suggest that the root cause of misconceptions was learners' prior knowledge, the teaching paradigm they had been exposed to, teaching practices and the over-generalisation of the whole number to the concept of fractions. This is discussed further below.

\section{Prior knowledge}

Our findings revealed that learners' prior knowledge of fundamental fraction concepts was either lacking or flawed. The resulting misconceptions affected their application of fractions in algebra and other contexts in Grade 9. From a cognitive constructivist perspective, when a learner interacts with an experience, situation or idea - in this instance a fraction concept - one of two things may happen: either the new experience is integrated with the person's existing schema, a process called assimilation, or the existing schema is adapted to accommodate the new idea or experience, a process called accommodation or adaptation (Piaget, 1964a). In this study, there was almost no evidence of assimilation of concepts into the learner's cognitive schema. There was little sign of integration of the idea of fractions (new experience) in learners' existing schema, which in this instance could have been knowledge of natural numbers. New knowledge of fractions was not assimilated by the appropriate schemata (cognitive ideas). The new concept of a fraction did not fit with concepts that were already part of learners' cognitive schemata. There was thus disequilibrium. The existing schema of natural numbers did not give meaning to new experiences with and ideas about fractions. Learners lacked the basic conceptual understanding of numerator and denominator that would have enabled them to understand what fractions are all about. 
In this study learners engaged in a process of adaptation, where they merely revised their existing knowledge to accommodate the new knowledge. The notion of the fraction did not fit into their existing schema, and instead of altering by assimilating the new fraction concepts, they 'forced' the new ideas into their unaltered existing schema. For example, the new knowledge of fractions should have been assimilated into their knowledge of natural and whole numbers, thus altering their number schema conceptually.

\section{Teaching paradigm}

From a cognitive constructivist perspective, we assign the failed acquisition of basic fraction concepts to, at least in part, the behaviouristic teaching of instrumental knowledge, which is the traditional pedagogical approach in many South African schools. In this style of teaching, learners passively receive the knowledge poured into them without being given the opportunity to construct meaning for themselves.

In the classrooms in which this study was conducted, learners were seated in orderly rows, and group discussion was kept to the minimum. In a contrasting approach, Cobb (1994) advocates that learners should construct mathematical knowledge experientially. In this way, they will learn to understand the world of their personal experiences. Ultanir (2012) agrees that real understanding is constructed through experience and not bestowed on the learner.

The findings of this study led us to conclude that a shift from the traditional approach of direct teaching to a constructivist approach is needed. In such an approach, knowledge acquisition is facilitated rather than bestowed; ideas are negotiated rather than imposed, and learners are actively involved in 'doing' mathematics rather than simply passively executing mathematics. It appeared from this study that learners were not engaged in constructing knowledge on their own by working through set tasks, allowing their minds to sift through the materials they were working with, and integrating new ideas with existing ones. Constructivism rejects the notion that children are 'blank slates' with no ideas, concepts and mental structures. They should be encouraged not merely to absorb ideas as teachers present them but, rather, to be creators of their understanding.

\section{Teaching practices}

Some pedagogies seem to have had a limiting effect on conceptual understanding:

- Most learners defined fractions from the part-of-a-whole perspective and their incorrect definitions were aligned with this sub-construct. We believe that the practice in teaching fractions of routinely shading parts of one whole geometric figure or cutting a pizza or a cake into pieces to indicate a fraction has to do with this limited conceptualisation (Deringöl, 2019; Van de Walle, 2016).

- The part-of-a-whole sub-construct addresses area model type situations and learners in this had not been exposed to the continuous model, as evidenced by their failure to comprehend equivalence questions. This corresponds to
Gabriel's (2016) argument that learners always consider fractions as entities smaller than 1; thus, they have difficulties placing fractions on the number line.

- Traditionally, there is an over-emphasis on whole number teaching and insufficient transitional bridging to rational numbers. It appears that prior knowledge of whole numbers encourages misunderstanding of the concept of fractions (Machaba, 2016).

- Rote teaching and learning of the elements of fractions, such as fraction notation (Jigyel et al., 2007) and terminology (Maharaj, Brijlall, \& Molebale, 2007), hamper true understanding. In this study, learners displayed rigidity in their dealings with equality, fraction representations and whole number over-generalisations. These aspects should become part of learners' active vocabulary, but because teachers do not serve as models by using fraction terminology in their everyday classroom discourse, this does not happen.

\section{Overgeneralisations}

This study found a generalisation of knowledge from whole numbers to work on fractions. Fractions were thus regarded either as two separate, unrelated whole numbers or a whole number divided by another whole number. We concur with Bruce et al. (2014) that this is the result of regarding a fraction as simply two whole numbers that can be treated separately. The fact that learners thought of the numerator and the denominator as separate values may have been because they used their knowledge of natural numbers when they encountered fractions. Olivier (1989), Machaba (2016) and Deringöl (2019) all found the source of these misconceptions to be mostly an overgeneralisation of previous knowledge (knowledge that was correct in an earlier domain) to an extended domain (where it was no longer valid). This meant that learners who had been taught whole or natural numbers in their early stages of learning, for instance, later overgeneralised this knowledge and extended it to other knowledge about fractions; while fractions are taught, their representation with symbols such as numerator and denominator is introduced without setting the conceptual basis for these symbols.

\section{Recommendations}

Analysis of the data revealed gaps in essential aspects of fraction knowledge that should have been dealt with at an earlier stage in these learners' education. We concluded that particular concepts were faulty. These included:

- equality of fractional parts

- the numerical conceptualisation of fraction notation

- the idea that the whole can comprise several objects

- the scope of fractions beyond 1 .

According to the specific knowledge and skills described in the Curriculum Assessment Policy Statement (CAPS) (DBE, 2011) document, these concepts are learned in Grade 3 and Grade 4, leading us to conclude that the problems that surfaced in Grade 9 originated with the transition from FP to IP. However, the 
mode of teaching is also developmentally appropriate for each phase. Drawing on the classical Piagetian cognitivedevelopmental theory as summarised by McLeod (2009), we regard the movement from concrete to abstract learning as a cognitively appropriate progression. In this conceptualisation, fraction learning should ideally follow a developmental sequence:

- The initial encounter with the notion of fractions would typically be taught experientially, using physical manipulatives, such as cutting an apple into equal parts or grouping a set of balls in equal quantity sub-sets.

- This would be followed by pictures of fractions, such as sketches or photographs of the apple pieces or the groups of balls.

- After this, diagrams, for example geometrical shapes such as circles and rectangles, would represent the fraction of a whole or sets.

- Once the concepts have been firmly established, learners can work with fraction symbols only, without the need for physical, pictorial or diagrammatic representations.

From what we have observed of the way learners responded and explained their understanding during interviews, we conclude that the traditional way of teaching fractions is to start with diagrams. Unfortunately, we could link several instances of fraction misconceptions to misinterpretations of diagrams and pictures. This suggests that teaching fractions primarily with the use of diagrams or geometrical shapes does not adequately support the development of fundamental fraction concepts. We found evidence that these diagrams often formed an integral part of the misconceptions (for instance, the typical 'shaded part').

In keeping with our approach of cognitive constructivism, we would therefore suggest a rethink of the building process of the fraction concept, starting with physical manipulatives, even if this is regarded as inappropriate at the Grade 9 level. Grade 9 learners cannot be introduced to algorithms without understanding the basics of fractions. This implies that learners must unlearn their misconceptions and relearn and solidify the basic concepts by constructing meaning from basic fractions concepts.

To design cognitively appropriate remedies, we therefore recommend that teachers diagnose misconceptions in the light of their manifestation, to establish at what point conceptualisation becomes problematic. The purpose is to deconstruct misconceptions at their point of origin by reconstructing foundational fraction concepts from the roots up. We believe that this is the path to structural cognitive modification, where new concepts are assimilated into existing schemata through relational (as opposed to instrumental) understanding.

\section{Acknowledgements Competing interests}

The authors declare no competing interest exists.

\section{Authors' contributions}

The involvement of the first author in this study was part of his master's research degree. The involvement of the second author, as a supervisor, was more on reconceptualising the article and writing it.

\section{Funding information}

This research received no specific grant from any funding agency in the public, commercial or not-for-profit sectors.

\section{Data availability}

Data were collected as a part of master's degree, which will be uploaded in the UNISA repository.

\section{Disclaimer}

The views and opinion expressed in this article are those of the authors and do not necessarily reflect the official policy or position of any affiliated agency of the authors.

\section{References}

Alghazo, Y. M., \& Alghazo, R. (2017). Exploring Common Misconceptions and Errors about Fractions among College Students in Saudi Arabia. International Education Studies, 10(4), 133-140.

Altıparmak, K., \& Özüdoğru, M. (2015). Error and misconception: Relation of fraction and part-whole. Journal of Human Sciences, 12(2), 1465-1483. https://doi. org/10.14687/ijhs.v12i2.3404

Ashlock, R.B. (2010). Error patterns in computation: Using error patterns to help each student learn. Boston, MA: Allyn \& Bacon.

Braithwaite, D.W., \& Siegler, R.S. (2018). Developmental changes in the whole number bias. Developmental Science, 21(2), e12541. https://doi.org/10.1111/desc.12541

Brown, B. (2019). Rational number understanding: The big picture, not the essence. South African Journal of Childhood Education, 9(1), 1-8.

Bruce, C., Bennett, S., \& Flynn, T. (2014). Fraction operations: Multiplication and division literature review. Unpublished manuscript. Curriculum and Assessment Branch, Trent University, Ontario Ministry of Education. Retrieved from http:// www.edutains.ca/resourcesMath/CE/LessonsSupports/Fractions/ FractionsOperationsmultimodal.pdf

Cobb, P. (1994). Where is the mind? Constructivist and sociocultural perspectives on mathematics development. Educational Researcher, 23(7), 13-20. https://doi. org/10.3102/0013189X023007013

Confrey, J. (1990). A review of research on student conceptions in mathematics, science and programming. In C. Cazden (Ed.), Review of research (pp. 3-56). Washington, DC: American Educational Research Association. http://dx.doi.
org $10.2307 / 1167350$

D’Ambrosio, B.S., \& Mewborn, D.S. (1994). Children's constructions of fractions and their implications for classroom instruction. Journal of Research in Childhood Education, 8(2), 150-161. https://doi.org/10.1080/02568549409594863

Department of Basic Education (DBE). (2011). National Curriculum Statement (NCS): Curriculum and assessment policy statement: Intermediate Phase. Grades 4-6. Mathematics. Pretoria: Department of Basic Education.

Department of Basic Education (DBE). (2014). The annual national assessment of 2014 diagnostic report, intermediate and senior phases mathematics. Pretoria: Department of Basic Education. Retrieved from www.education.gov.za

Deringöl, Y. (2019). Misconceptions of primary school students about the subject of fractions. International Journal of Evaluation and Research in Education, 8(1), 29-38. https://doi.org/10.11591/ijere.v8i1.16290

Doyle, K.M., Dias, O., Kennis, J.R., Czarnocha, B., \& Baker, W. (2016). The rational number sub-constructs as a foundation for problem-solving. Adults Learning Mathematics, 11(1), 21-42.

Durkin, K., \& Ritle-Johnson, B. (2014). Diagnosing misconceptions: Revealing changing decimal fraction knowledge. Learning and Instruction, 37, 21-29. https://doi. org/10.1016/j.learninstruc.2014.08.003

Fitri, N.L., \& Prahmana, R.C.I. (2019). The misconception in fraction for seventh-grade students. Journal of Physics: Conference Series, 1188(1), 012031. https://doi. org/10.1088/1742-6596/1188/1/012031 
Gabriel, F. (2016). Understanding magnitudes to understand fractions. Australian Primary Mathematics Classroom, 21(2), 36-40.

Gupta, R., \& Gupta, V. (2017). Constructivist approach in teaching. International Journal of Humanities and Social Sciences, 6(5), 77-88.

Hatano, G. (1996). A conception of knowledge acquisition and its implications for mathematics education. In L. Steffe, P. Nesher, P. Cobb, \& G. Goldin (Eds.), Theories of mathematical learning (pp. 197-217). Hillsdale, NJ: Lawrence Erlbaum.

Jigyel, K., \& Afamasaga-Fuata'i, K. (2007). Students' conceptions of models of fractions and equivalence. Australian Mathematics Teacher, 63(4), 17-25.

Kieran, C. (1981). Concepts associated with the equality symbol. Educational studies in Mathematics, 12(3), 317-326.

Laridon, P., Brown, M., Jawurek, A., Mbatha, L., Mbatha, P., Scheiber, J. ... Wilson, H. (2005). Classroom mathematics, Grade 7 learners' book. Johannesburg: Heinemann.

Machaba, F.M. (2016). The concepts of area and perimeter: Insights and misconceptions of Grade 10 learners. Pythagoras, 37(1), 1-11. https://doi. org/10.4102/pythagoras.v37i1.304

Maharaj, A., Brijlall, D., \& Molebale, J. (2007). Teachers' views of practical work in the teaching of fractions: A case study. South African Journal of Education, 27(4), 597-612.

McLeod, S.A. (2009). Jean Piaget. Retrieved from http://www.simplypsychology.org/ piaget.htm

$\mathrm{Ni}$, Y., \& Zhou, Y. D. (2005). Teaching and learning fraction and rational numbers: The origin and implications of whole number bias. Educational psychologist, 40(1), $27-52$.

Noureen, G., Arshad, T., \& Bashir, M. (2020). Effect of constructivist teaching approach on student's achievement in science at the elementary level. Pakistan Socia Sciences Review, 4(III), 904-911. https://doi.org/10.35484/pssr.2020(4-III)64

Ojose, B. (2015). Misconceptions in mathematics, strategies to correct them. Lanham, MD: University Press of America.

Olivier, A. (1989). Handling pupil's misconceptions. Pythagoras, 21, 10-19.

Piaget, J. (1964a). Cognitive development in children: Piaget development and learning. Journal of Research in Science Teaching, 2(3), 176-186. https://doi org/10.1002/tea.3660020306

Piaget, J. (1964b). Development and learning. In R.E. Ripple \& V.N. Rockcastle (Eds.) Piaget rediscovered (pp. 7-20). Retrieved from http://www.psy.cmu.edu/siegler/35piaget64.pdf

Pitkethly, A., \& Hunting, R. (1996). A review of recent research in the area of initial fraction concepts. Educational Studies in Mathematics, 30(1), 5-38. https://doi. org/10.1007/BF00163751
Prediger, S. (2006). The relevance of didactic categories for analysing obstacles in conceptual change: Revisiting the case of multiplication of fractions. Dortmund: Institute for Development and research in Mathematics Education, University of Dortmund.

Resnick, L.B., Nesher, P., Leonard, F., Magone, M., Omanson, S., \& Peled, I. (1989). Conceptual bases of arithmetic errors: The case of decimal fractions. Journal for Research in Mathematics Education, 20(1), 8-27. https://doi.org/10.2307/ 749095

Sarwadi, H.J. \& Shahrill, M. (2014). Understanding students' mathematical errors and misconceptions: The case of Year 11 repeating students. Mathematics Education Trends and Research, 2014(2014), 1-10. https://doi.org/10.5899/2014/metrTrends

Siegler, R.S., Thompson, C.A., \& Schneider, M. (2011). An integrated theory of whole number and fractions development. Cognitive Psychology, 62(4), 273-296. number and fractions development. Cognitive
https://doi.org/10.1016/j.cogpsych.2011.03.001

Simon, M.A., Placa, N., Avitzur, A., \& Kara, M. (2018). Promoting a concept of fractionas-measure: A study of the Learning Through Activity research program. The Journal of Mathematical Behavior, 52, 122-133. https://doi.org/10.1016/j. jmathb.2018.03.004

Skemp, R. (1976). Relational understanding and instrumental understanding Mathematics Teaching (77), 20-26.

Smith, J.P.III, DiSessa, A.A., \& Roschelle, J. (1994). Misconceptions reconceived: A constructivist analysis of knowledge in transition. Journal of the Learning Sciences, 3(2), 115-163. https://doi.org/10.1207/s15327809jls0302_1

Stafylidou, S., \& Vosniadou, S. (2004). The development of students' understanding of the numerical value of fractions. Learning and Instruction, 14(5), 503-518. https:// doi.org/10.1016/j.learninstruc.2004.06.015

Ultanir, E. (2012). An epistemological glance at the constructivist approach: Constructivist learning in Dewey, Piaget and Montessori. International Journal of Instruction, 5(2), 195-212.

Vamvakoussi, X. \& Vosniadou, S. (2010). How many decimals are there between two fractions? Aspects of secondary school students' understanding of rational numbers and their notation. Cognition and Instruction, 28(2), 181-209. https:// doi.org/10.1080/07370001003676603

Van de Walle, J.A., Karp, K.S., \& Bay-Williams, J.M. (2016). Elementary and middle school mathematics. London: Pearson Education UK.

Van de Walle, J.A., Folk, S., \& Bay-Williams, J.M. (2010). Elementary and middle school mathematics: Teaching developmentally (7th ed.). Boston, MA: Allyn \& Bacon. 